1. MBBS, M. Phil (Hematology) Associate Professor Pathology

Sahiwal Medical College, Sahiwal

2. MBBS, FCPS (Hematology)

Assistant Professor Pathology

Punjab PGMI/LGH /

Ameerudin Medical College, Lahore

3. MBBS, M. Phil (Hematology)

Assistant Professor Pathology

Allama Iqbal Medical College,

Lahore

4. MBBS, M. Phil (Hematology)

Assistant Professor Pathology

Gomal Medical College, DIKhan

5. MBBS, FCPS (Hematology)

Sr. Demonstrator Pathology

Allama Iqbal Medical College,

Lahore

6. B.Sc (Hons) Medical Lab Technology

Medical Lab Technologist Allama Iqbal Medical College,

Lahore

Correspondence Address:

Dr. Mizna Arif

Assistant Professor Pathology

Punjab PGMI/LGH/

Ameerudin Medical College, Lahore

miznahrida06@gmail.com

Article received on:

09/04/2016

Accepted for publication:

$17 / 05 / 2016$

Received after proof reading:

04/05/2016

\section{SPECTRUM OF PANCYTOPENIA;}

A TERTIARY CARE EXPERIENCE

\begin{abstract}
Dr. Tariq Hameed Rehmani', Dr. Mizna Arif ${ }^{2}$, Dr. Sajjad Haider ${ }^{3}$, Dr. Sarah Arif $^{4}$, Dr. Rabia Ahmad ${ }^{5}$
\end{abstract} Muhammad Saeed ${ }^{6}$

ABSTRACT... Pancytopenia refers to a reduction in all the three cellular elements of blood. Pancytopenia is a common but important hematological problem encountered in routine clinical Practice. It may be a presenting feature of many underlying serious and life threatening illnesses. Objective: Present study was planned to appraise various clinico- etiological factors underlining Pancytopenia. Study Design: Cross-sectional study. Setting: Hematology Department of Allama lqbal Medical College/ Jinnah Hospital Lahore (AIMC\&JHL). Period: July 2011 to Jun 2015. Materials and Methods: Two hundred and forty four patients with Pancytopenia were included in the study. Complete blood count, bone marrow aspirations and trephine biopsies were performed after clinical history and physical exam. Data were analyzed by using SPSS 20.0 version. Results: Out of total 244 Pancytopenia cases, hypoplastic bone marrow 66 (27.04\%) and Megaloblastic anemia 49 (20.08\%) were the most common etiological factors with male predominance. Fever and pallor were striking presenting clinical features. Conclusion: We conclude that Pancytopenia is a common problem with an exhaustive list of differential diagnosis, some of which are easily treatable and reversible. Therefore early detection with optimal diagnostic approach to Pancytopenia is required for better management of patients.

Key words: $\quad$ Pancytopenia, Aplastic anemia, Megaloblastic anemia, Bone marrow.

Article Citation: Rehmani TH, Arif M, Haider S, Arif S, Ahmad R, Saeed M. Spectrum of pancytopenia; a tertiary care experience. Professional Med J 2016;23(5):620626. DOI: $10.17957 / T P M J / 16.3398$
INTRODUCTION

Pancytopenia is an important hematological condition characterized by reduction in all major cell lines i.e., red cells, white cells as well as platelets in peripheral blood resulting in Anemia, Thrombocytopenia and Leucopenia leading to symptoms of fatigue, bruising and susceptibility to infections respectively. ${ }^{1}$

Therefore Pancytopenia occurs when hemoglobin is less than $13.5 \mathrm{~g} / \mathrm{dl}$ in males, $11.5 \mathrm{~g} / \mathrm{dl}$ in females, the WBC count is less than $4 \times 109 / L$ and platelet count is less than $150 \times 109 /$ L. $^{2}$

Pancytopenia is not a disease itself and can be a presenting feature of innumerable underlying disorders. It has variable etiology which can be broadly classified into causes due to decreased bone marrow function such as Aplasia, Infiltration, Ineffective erythropoiesis such as Megaloblastic anemia etc or increased peripheral destruction such as splenomegaly. ${ }^{3}$

Pancytopenia most often occurs after anticancer chemotherapy and HIV infection. ${ }^{4}$

Since Pancytopenia can be a feature of many serious and life threatening diseases, therefore optimal diagnostic approach is required to identify the correct cause of Pancytopenia which will help in better management and prognosis of such patients. ${ }^{5}$

Geographical distribution and genetic variations influence the incidence of various disorders causing Pancytopenia in different populations according to age, sex, race, nutritional deficiencies and prevalence of certain infections such as Hepatitis C, HIV etc. ${ }^{6}$ 
Extensive workup of Pancytopenia is required to diagnose underlying pathology including careful clinical examination, any drug history, and environmental exposure. ${ }^{7}$ After analyzing peripheral blood smear, bone marrow aspirate, trephine biopsy and additional testing is recommended in cases of undiagnosed Pancytopenia. $^{8}$

\section{MATERIALS AND METHODS}

Present study was conducted in Hematology Department of Allama Iqbal Medical College/ Jinnah Hospital Lahore from July 2011 to June 2015. Two hundred and forty four male and female patients presenting with Pancytopenia, between ages $10-70$ years, attending or admitted through OPD/Indoor of Jinnah Hospital Lahore were included in this study.

Patients receiving chemotherapy for malignancy or who had received platelet transfusions recently were excluded from the study.

A detailed clinical history, drug history, nutritional history was taken from patients as well as complete physical exam was done. Hematological investigations such as Complete blood count (CBC) were analyzed by Sysmex KX-21 with blood sample taken in EDTA tube. Pancytopenia was diagnosed in the presence of anemia (hemoglobin $<11 \mathrm{~g} / \mathrm{dl}$ ), leucopenia (total leukocyte count [TLC] $<4,000 / \mathrm{mm} 3$ ), and thrombocytopenia (platelet count $<150,000 / \mathrm{mm} 3$ ). Platelet counts were further verified manually.

Supravital staining was used for Reticulocyte count. Peripheral smears, Bone marrow aspirate, trephine biopsy and Malaria parasite smears was stained with Giemsa for microscopy. Bone marrow exam was done under aseptic technique after obtaining informed consent from patient/ guardian.

Special stains like Prussian blue stain, Reticulin stain; Myeloperoxidase, Sudan black and Masson's trichrome stain were done.

Further Investigations were carried out when indicated clinically to diagnose and evaluate the underlying cause of Pancytopenia such as serum iron profile, B12/Folate levels, bone marrow cultures, Malaria parasite, Liver function test, hepatitis viral serology, HIV, ultrasound for liver, spleen or other abdominal pathology, Immunomarkers for NHL and Bone marrow Metastasis. All this information was entered in specifically designed Performa.

Data was analyzed using SPSS version 19.0. Statistical analysis was done by applying descriptive stats (mean, SD, frequency distribution, percentages) etc.

\section{RESULTS}

During the study period starting from July 2011 to June 2015, a total of 244 patients fulfilling the criteria of Pancytopenia according to the study protocol and coming to hematology department at AIMC/JHL Teaching Hospital from OPD/Indoor units were included, out of which 145 were males and 99 were females with male to female ratio of 1.46:1. Age range was 10-70 years. The largest number of cases was found in the age group (Table-I) of $21-30$ years (32.78\%) followed by the age groups of 10-20years (29.09\%) and 51-60 years $(15.57 \%)$.

\begin{tabular}{|c|c|c|}
\hline & Frequency & Percentage \\
\hline Male & 145 & $59.42 \%$ \\
\hline Female & 99 & $40.57 \%$ \\
\hline $10-20$ & Age Group & \\
\hline $21-30$ & 71 & $29.09 \%$ \\
\hline $31-40$ & 80 & $32.78 \%$ \\
\hline $41-50$ & 29 & $11.88 \%$ \\
\hline $51-60$ & 20 & $8.19 \%$ \\
\hline $61-70$ & 34 & $15.57 \%$ \\
\hline Total & 10 & $4.09 \%$ \\
\hline
\end{tabular}

Table-I. Frequency distribution according to gender \& age group

The commonest presenting complaint (Fig-1) was pallor in $50.1 \%(154 / 244)$ followed by fever in $42.6 \%(104 / 244)$ and bleeding in \% 23.7(58/244) of the cases. Splenomegaly was seen in $15.1 \%$ $(37 / 244)$, while hepatomegaly was observed in $9.8 \%(24 / 244)$ and lymphadenopathy in $13.1 \%$ ( $32 / 244)$ of the cases. 

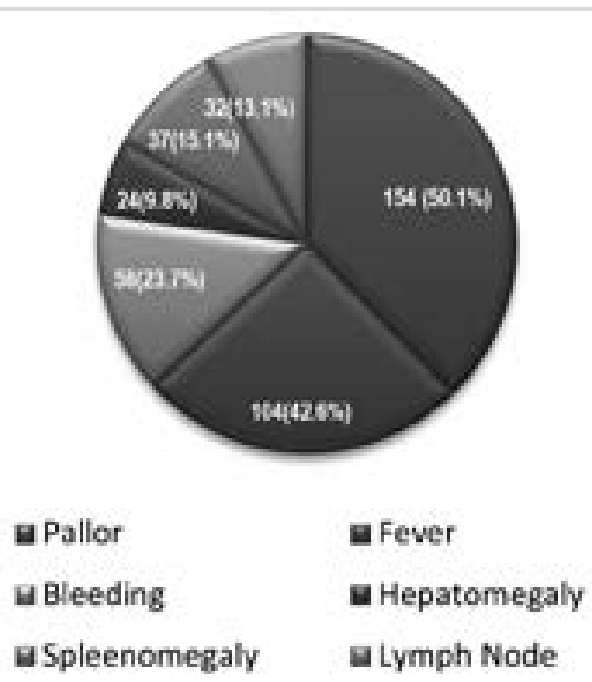

Fig-1. Frequency percentage of different presenting complaints in patients with Pancytopenia

The most common cause of Pancytopenia (Fig2) in all these 244 patients was Aplastic anemia observed in 66 out of 244 patients. Next common cause was Megaloblastic anemia (49/244), Acute leukemia (35/244) and Double deficiency (30/244) anemia followed by Chronic disorders
(18/244) which included Chronic liver disease (4), Tuberculosis (11), and HIV (3) infections and Myelofibrosis(16/244). Out of 35 Acute leukemia cases, 21 were Acute lymphoblastic leukemia and rest were cases of Acute myeloid leukemia.

A large number of patients were diagnosed of having Malaria (9/244). Few cases of non Hodgkin lymphoma (7/244) and Myelodysplastic syndrome (5/244) were seen. Hypersplenism due to various causes was found in (4/244) patients. Less common causes recorded were bone marrow metastatic disease (3/244) and rare causes were found as multiple myeloma (1/244) and leishmaniasis (1/244).

\section{DISCUSSION}

Pancytopenia is a manifestation of many transient as well as some life threatening disease processes leading to anemia, leucopenia and thrombocytopenia simultaneously in peripheral blood of patient. ${ }^{9}$ The different causes of Pancytopenia may be attributed to multitude of factors such as geographical and genetic variations, nutrition, prevalence of certain

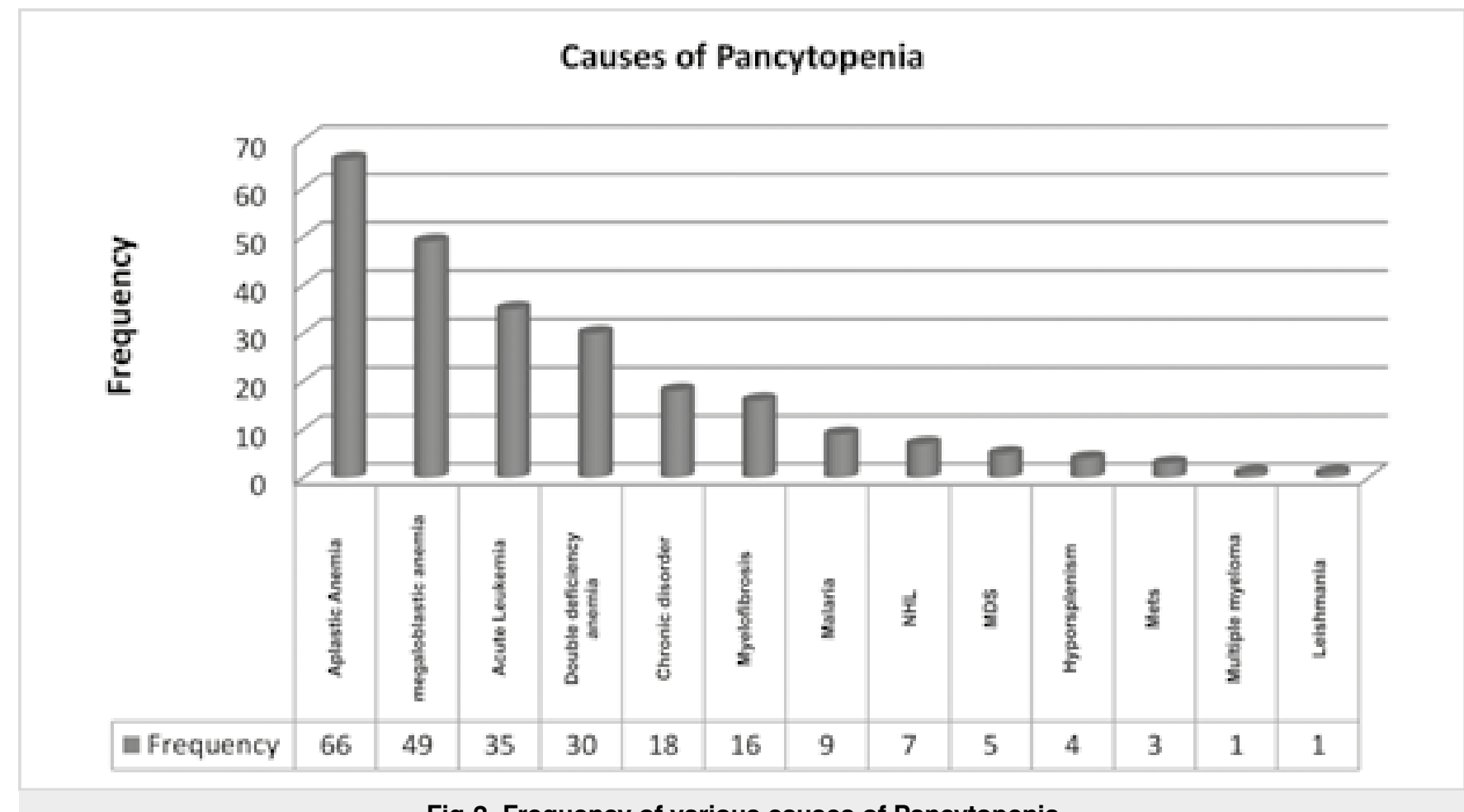

Fig-2. Frequency of various causes of Pancytopenia 
infections and exposure to toxic chemicals and drugs etc in a particular population under study. ${ }^{10}$ Also varying patterns of diagnostic modalities and patient referral systems in different countries play a key role in determining frequency of underlying causes of Pancytopenia in different populations. Identification of proper underlying cause is very important in planning of subsequent management of such patients in proper manner. ${ }^{11}$

Although Pancytopenia is a common presenting feature of many underlying disorders, yet to our knowledge, there are only a limited number of studies in the literature evaluating clinico etiological spectrum of Pancytopenia. In the literature there is evidence showing variable frequencies of etiology of Pancytopenia in different studies. ${ }^{12}$

In this study a total number of 244 cases of Pancytopenia were studied. Age, sex distribution, presenting complaints and various causes of Pancytopenia were studied in all these cases, and observations were compared with studies already published in Pakistan as well as other neighboring parts of the world.

In our study male predominance was noted in all the age groups with male to female ratio being $1.46: 1$ which is comparable to other studies done by Ameileena $\mathrm{C}$, et al. ${ }^{13}$ and Jha, et al. ${ }^{14}$ with reported male to female ratio of $1.64: 1$ and $1.5: 1$ respectively.

In the present study Pallor (90\%) was the commonest clinical manifestation followed by Splenomegaly (15.1\%) hepatomegaly (13.1\%) and lymphadenopathy (9.8\%). We also found that Fever (42.6\%) was the most common presenting complaint in our study population preceded by bleeding manifestations (23.7\%). Similarly Pallor and splenomegaly were also commonest signs observed by Niazi $\mathrm{M}$ et $\mathrm{al}^{15}$ however generalized weakness was the most common symptom(68.2\%) followed by fever (47.7\%) and bleeding manifestations(33.33\%) in that study which is different from our study.
The most common cause of Pancytopenia in our study was Aplastic anemia (66/244) followed by Megaloblastic anemia (49/244). These findings are consistent with results of Niazi and Raziq et al., ${ }^{15}$ however Aplastic anemia was the second most common etiology in a study by Khodke et al ${ }^{16}$, and Kumar et al ${ }^{17}$ while first cause was Megaloblastic anemia.

It is the commonest cause of Pancytopenia reported from various studies throughout the world. ${ }^{18}$ Epidemiology of Aplastic anemia shows higher frequency in the developing world than in industrialized Western countries. An annual incidence of two new cases per million populations in Europe. Studies from Thailand and China shows the incidence to be about three-fold than in the West. The exact incidence of Aplastic anemia in Pakistan is not known due to lack of population-based studies. ${ }^{19}$

Auto-immune mechanism is implicated as etiology of Aplastic anemia. ${ }^{20}$ Majority of the patients with Aplastic anemia in this study had underlying hepatitis C disease, Systemic lupus (SLE), Sickle cell disease or history of exposure to pesticides. Few patients gave history of drug exposure such as Pyrimethamine-sulfamethaxazole, Interferon, NSAIDs, anticonvulsants and rest had idiopathic cause. ${ }^{21}$

Ineffective hemopoiesis leads to development of Pancytopenia in Megaloblastic anemia.

Vitamin B12 deficiency was found to be more common than Folate deficiency in patients with Megaloblastic anemia, in the present study. This is consistent with the results of similar studies conducted in Pakistan India and its neighboring countries. $^{22}$

An important cause of Pancytopenia in our study was mixed dietary deficiency of Iron and B12/ Folic acid found in thirty patients. A possible explanation of such large number of patients presenting with nutritional anemia can be extremes of age, Nutritional deficiencies, malabsorption, parasitic infestations, chronic gastrointestinal or 
genitourinary bleed etc.

Since nutritional disorders are easily treatable therefore should be considered at higher order in differential diagnosis list of Pancytopenia. ${ }^{23}$

Megaloblastic anemia and combined deficiency is a common cause of Pancytopenia in various other studies comparable with our research. ${ }^{23}$ Malignancies like acute leukemia, bone marrow metastasis and Non Hodgkin lymphomas are more common and dangerous causes of Pancytopenia especially in developed part of the world as evidenced by work of Keisu $M$ and Ost $A^{7}$. We encountered 35 cases of acute leukemia making it third most common etiology of Pancytopenia, consistent with findings of Rathod and Alwani. ${ }^{24}$

$\mathrm{NHL}$ and Mets were diagnosed in 7 and 3 cases respectively in our study making them less common causes of Pancytopenia and it is comparable with findings of Pathak and Jha. ${ }^{25}$

MDS constituted only 5 cases in four years and single cases of Visceral leishmaniasis (Kalaazar) as well as multiple myeloma were among the rare causes of Pancytopenia in our study comparable with Khunger JM et al. ${ }^{26}$

Hypersplenism was found to be another less common cause of Pancytopenia in our study which is in sharp contrast with research of Ashraf et al ${ }^{27}$ from our part of the world showing Hypersplenism to be leading cause of Pancytopenia.

According to Prem Kumar et $\mathrm{al}^{28}$ in developing countries Pancytopenia is mostly attributed to infectious diseases such as tuberculosis and HIV which correlates well with our study that shows a large chunk of Pancytopenia cases were due to chronic disorders including TB and HIV. Nine cases of malaria had Pancytopenia in our study. Direct invasion of bone marrow by parasite, hemphagocytosis, disseminated intravascular coagulation and Hypersplenism are few of the factors contributing to development of Pancytopenia in Malaria. These findings were reported by Tareen etal ${ }^{29}$ who observed thatmalaria was the most common cause of Pancytopenia. Another important cause of Pancytopenia reported in literature is Myelofibrosis. We discovered Myelofibrosis to be an important and not less common etiology of Pancytopenia but contrasting evidence is reported otherwise such as Anita and Vijay research shows Myelofibrosis to be one of rare causes of Pancytopenia. ${ }^{30}$

A comparative analysis of present study with different studies in literature is presented in tabulated form. (Table-II).

\begin{tabular}{|c|c|c|c|c|c|c|}
\hline $\begin{array}{l}\text { Serial } \\
\text { No }\end{array}$ & Author & $\begin{array}{l}\text { Study } \\
\text { year }\end{array}$ & $\begin{array}{l}\text { Country/ } \\
\text { population }\end{array}$ & $1^{\text {st }}$ Cause $\%$ & $2^{\text {nd }}$ Cause $\%$ & Ref \\
\hline 1 & $\begin{array}{l}\text { Tilak and Jain } \\
\text { et al }\end{array}$ & 1999 & India & $\begin{array}{l}\text { Megaloblastic } \\
(68.0)\end{array}$ & $\begin{array}{c}\text { Aplastic } \\
(7.7)\end{array}$ & 18 \\
\hline 2 & Khodke et al & 2000 & India & $\begin{array}{l}\text { Megaloblastic anemia } \\
(44.0)\end{array}$ & $\begin{array}{c}\text { Aplastic anemia } \\
(14.0)\end{array}$ & 16 \\
\hline 3 & Niazi and Raziq et al & 2004 & Pakistan & $\begin{array}{c}\text { Aplastic anemia } \\
\quad(38.7)\end{array}$ & $\begin{array}{c}\text { Megaloblastic anemia } \\
(24.7)\end{array}$ & 15 \\
\hline 4 & Lakhey et al & 2012 & Nepal & $\begin{array}{l}\text { Hypoplastic anemia } \\
\text { (29.6) }\end{array}$ & $\begin{array}{l}\text { Hematological malignancies } \\
\text { (27.7) }\end{array}$ & 4 \\
\hline 5 & Ashraf et al & 2010 & Pakistan & $\begin{array}{l}\text { Hypersplenism } \\
(68.0)\end{array}$ & $\begin{array}{c}\text { Megaloblastic anemia } \\
(24.5)\end{array}$ & 27 \\
\hline 6 & Present study & 2015 & Pakistan & $\begin{array}{c}\text { Aplastic anemia } \\
(27.0)\end{array}$ & $\begin{array}{c}\text { Megaloblastic anemia } \\
(20.0)\end{array}$ & -- \\
\hline
\end{tabular}




\section{CONCLUSION}

Present study concludes that Pancytopenia is a fairly common clinical problem in adults as well as pediatric patients. The etiology of Pancytopenia is multifactorial and comprises of a large spectrum of diseases ranging from simple treatable conditions such as Megaloblastic Anemia, double deficiency anemia, Malaria to more serious, life threatening disorders such as Aplasia, Malignancy and metastasis. It should be considered clinically and thoroughly investigated in patients who present with complaints of fever, unexplained pallor and bruising/bleeding because correct identification of underlying cause can result in early diagnosis, better treatment and prognosis of patients. In present study it is concluded that Aplastic anemia is the most common cause of Pancytopenia in our study population followed by easily treatable Megaloblastic anemia and mixed iron plus B12/ Folate deficiency anemia especially in younger patients, however rare and serious causes of Pancytopenia such as multiple myeloma and HIV infection should not be ignored while planning for complete work-up of Pancytopenia patients.

It is also suggested in present study that more studies with large sample size should be conducted at National level so as to implement and improve better treatment protocols for lethal diseases such as Aplastic anemia and acute leukemia, lymphoma especially in young patients to reduce morbidity and mortality.

Copyright@ 17 May, 2016.

\section{REFERENCES}

1. Tariq M, Khan N, Basri R, Amin S. Aetiology of Pancytopenia. Professional Med J 2010;17:252-6.

2. Gupta V, Tripathi S, Tilak V, Bhatia BD. A study of clinichematological profiles of Pancytopenia in children. Trop Doct. 2008; 38(4); 241-43.

3. Santra G, Das BK. A cross sectional study of the clinical profile and etiological spectrum of Pancytopenia in a tertiary care center. Singapore Med J. 2010; 51(10): 806-12.

4. Lakhey A, Talwar OP, Singh VP, Shiva Raj KC. Clinicohaematological study of Pancytopenia. J Pathol Nepal.2012;2:207- 10.
5. Osama I, Haider ZB, Anwer F, Nisar H. Patterns of Pancytopenia patients in a general medical ward and a proposed diagnostic approach. J Ayub Med Coll Abbottabad 2004; 16: 8-13.

6. Mussarrat $N$, Fazl $R$. The incidence of underlying pathology in Pancytopenia - an experience of 89 cases. Journal of Postgraduate Institute, Peshawar 2004; 18: 76-9.

7. Keisu M, Ost A. Diagnosis in patients with severe Pancytopenia suspected of having Aplastic anemia. Eur J Haematol 1990; 45: 11-4.

8. Kishor K, Marwah S, Buxi G, Yadav RB, Chaturvedi NK. Bone marrow examination in cases of Pancytopenia. Journal Indian Academy of Clinical Medicine 2001; 2: 55-9.

9. Savage DG, Allen RH, Gangaidzo IT, Levy LM, Gwanzura $\mathrm{C}$, et al. Pancytopenia in Zimbabwe. Am J Med Sci. 1999; 317: 22- 32.

10. Shishir KB, Jagdish $C$, Shashi N, Sunita S, Varinder $\mathrm{S}$, Ashok KD. Pancytopenia in children: etiological profile. Journal of Tropical Pediatrics, New Delhi, India 2005; 51: 236-9.

11. Varma $\mathrm{N}$, Dash $\mathrm{S}$. A reappraisal of underlying pathology in adult patients presenting with Pancytopenia. Trop Geogr Med 1992;44:322- 7.

12. Raphael V, Khonglah Y, Dey B, Gogoi P, Bhuyan A: Pancytopenia: an etiological profile. Turk $\mathrm{J}$ Hematol 2012, 29:80-81.

13. Ameileena C, Vipan C, Anubhava P, Harish C. Clinicoaetiological profile of Pancytopenia in pediatric practice. JIACM, 2012; 13(4): 282-5.

14. Jha A, Sayami G, Adhikari RC, Panta AD, Jha R. Bone Marrow Examination in Cases of Pancytopenia. J Nepal Med Assoc 2008; 47(169): 12-7.

15. Niazi $M$, Fazl-i-Raziq. The incidence of underlying pathology in Pancytopenia - An experience of $\mathbf{8 9}$ cases. 2004; 18(1): 76-79.

16. Khodke K, Marwah S, Buxi G, Vadav RB, Chaturvedi NK. Bone marrow examination in cases of Pancytopenia. J Academy Clin Med. 2001; 2(1-2): 55-59.

17. Kumar R, Kalra SP, Kumar $H$, Anand AC, Madan $H$. Pancytopenia - a six year study. J Assoc Physicians India 2001; 49: 1078- 81.

18. Young NS. Acquired Aplastic anemia. In: Young NS, Gerson SL, High K, eds. Clinical Hematology. Philadelphia, PA: Elsevier; 2006: 136-157. 
19. Yang $C$, Zhang $X$. Incidence survey of Aplastic anemia in China. Chin Med Sci J 1991; 6: 203-7.

20. Young NS. Hematopoietic cell destruction by immune mechanisms in acquired Aplastic anemia. Semin Hematol 2000; 37: 3-14.

21. Acharya S, Bussel JB. Hematologic toxicity of sodium valporate. J Pediatr Hematol Oncol 2000; 22: 62-5.

22. Khanduri $U$ and Sharma A. Megaloblastic anemia: Prevalence and causative factors. Natl Med J India. 2007; 20: 172-175.

23. Bhagwan Singh Yadav et al., Clinical Profile of Pancytopenia: A Tertiary Care Experience, Int. J. Bioassays, 2015; 4 (01): 3673- 77.

24. Rathod GB, Alwani M, Patel H, Jain A. Clinicohematological analysis of Pancytopenia in Pediatric patients of tertiary care hospital. IAIM, 2015; 2(11): 15-19.

25. Pathak R, Jha A, Sayami G. Evaluation of bone marrow in patients with Pancytopenia. J Nepal Med Assoc 2012; 2: 265-71.

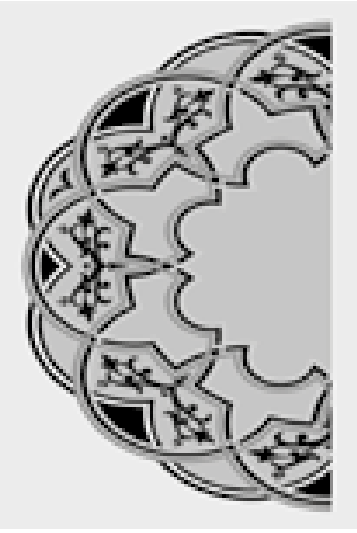

26. Khunger JM, Arulselvi S, Sharma U, Ranga S, Talib VH. Pancytopenia-a clinico hematological study of 200 cases. Indian J Pathol Microbiol 2002; 45:375- 9.

27. Asharaf S, Naeem S: Frequency of Hypersplenism in chronic liver disease patients with Pancytopenia. Annals of King Edward Medical University, North America, Special Edition Annals Jan - Mar (SI) 2010, 16(1):108-110. Available at: http://www.annalskemu. org/journal/index.php/annals/article/view/172/158.

28 Premkumar M, Gupta N, Singh T, Velpandian T. Cobalamin and folic Acid status in relation to the etiopathogenesis of Pancytopenia in adults at a tertiary care centre in north India. Anemia 2012; 2012:707402.

29. Tareen SM, Bajwa MA, Tariq MM, Babar S, Tareen AM. Pancytopenia in two national ethnic groups of Baluchistan. J Ayub Med Coll Abbottabad 2011; 23(2): 82-6.

30. Anita P. Javalgi and Vijay D. Dombale, Bone Marrow Study in Pancytopenia. National Journal of Laboratory Medicine. 2013 Dec; 2(4): 12-17.

\section{“Don't rush things. When the time is right it will happen."}

\section{AUTHORSHIP AND CONTRIBUTION DECLARATION}

\begin{tabular}{c|r} 
Sr. \# & Author-s Full \\
\hline 1 & Dr. Tariq Hameed \\
2 & Dr. Mizna Arif \\
\hline 3 & Dr. Sajjad Haider \\
4 & Dr. Sarah Arif \\
5 & Dr. Rabia Ahmad \\
\hline
\end{tabular}

6 Muhammad Saeed

Unknown

$\quad$ Contribution to the paper
Study conceptualization
Manuscript writing
Study conceptualization,
Manuscript writing, data
collection \& interpretation
Manuscript writing, Data
collection \& interpretation
Manuscript writing Review
of cases, Proof reading
Data collection and
interpretation, Review of
cases, Proof reading
Statistical analysis, Sample
collection, Lab work

